\title{
Siria: encrucijada territorial de actores geopolíticos regionales y globales ${ }^{1}$
}

\author{
Stella Maris Shmite, Gustavo Gastón Pérez y María Cristina Nin \\ Departamento e Instituto de Geografía (UNLPam) \\ @ [ shmite_stella@yahoo.com.ar ]| [ gustavoperez24@gmail.com ]| [ninmcristina@gmail.com ]
}

DOI: http://dx.doi.org/10.19137/huellas-2017-2107

\section{Introducción ${ }^{2}$}

Tos conflictos armados constituyen una de las manifestaciones más - crueles de las tensiones geopolíticas. Sus causas, así como la dispersión territorial y las consecuencias sobre la población afectada, son temas de interés de la Geografía. La guerra civil en Siria comenzó en 2011 y aún no finalizó, la crisis prolongada provoca cientos de miles de fallecidos, desplazados internos y refugiados. Se estima que más de 250.000 personas murieron desde el inicio de los enfrentamientos, unos siete millones y medio de ciudadanos sirios se encuentran desplazados dentro de su territorio, y aproximadamente, cuatro millones son refugiados o solicitantes de asilo.

En este marco, se aborda el conflicto interno en Siria y la guerra regional como problemáticas sociales relevantes, enmarcadas en la perspectiva geográfica. Oriente Medio está atravesado por profundas y complejas relaciones de poder entre actores regionales y mundiales. Durante el siglo

1 Panel "Guerra en Siria. La trama geopolítica regional y sus consecuencias en la población civil" organizado por el Instituto de Geografía en el marco del Proyecto de Investigación "Territorios dinámicos, tramas complejas. Deconstruyendo las relaciones de poder, los actores y las tensiones en diferentes escalas". Esta actividad se desarrolló el 11 de diciembre de 2015, aprobada por Resolución № 940/15 - CD - FCH - UNLPam.

2 Este texto fue revisado, actualizado y adaptado para esta publicación. Si bien participaron otros panelistas, esta presentación sintetiza las siguientes exposiciones: "Claves del orden geopolítico regional" por Stella Maris Shmite; "La guerra en Siria: evolución, actores y consecuencias" por Gustavo Gastón Pérez, y "Guerra y migraciones forzadas: problema geopolítico del siglo XXI" por María Cristina Nin. 
XX, y luego de la caída del Imperio Otomano, las potencias europeas, en este caso Francia y Reino Unido, rediseñaron las fronteras territoriales en distintas esferas de influencia hasta el momento de las independencias nacionales. En el presente, los antagonismos entre los liderazgos regionales se manifiestan también en el conflicto sirio. Arabia Saudita, Irán y Turquía son actores fundamentales que defienden sus intereses particulares a expensas de la situación en Siria e Irak. De igual modo, el tablero geopolítico regional cuenta con la participación de una coalición entre Estados Unidos y algunos países europeos, más las intervenciones de la Federación Rusa en su intento de reposicionarse como potencia de alcance global y mantener sus pretensiones geoestratégicas en la costa mediterránea. Asimismo, no debe soslayarse la participación de grupos kurdos que, diseminados por los países de la región, intentan recuperar en la actual coyuntura la autonomía de sus territorios ancestrales.

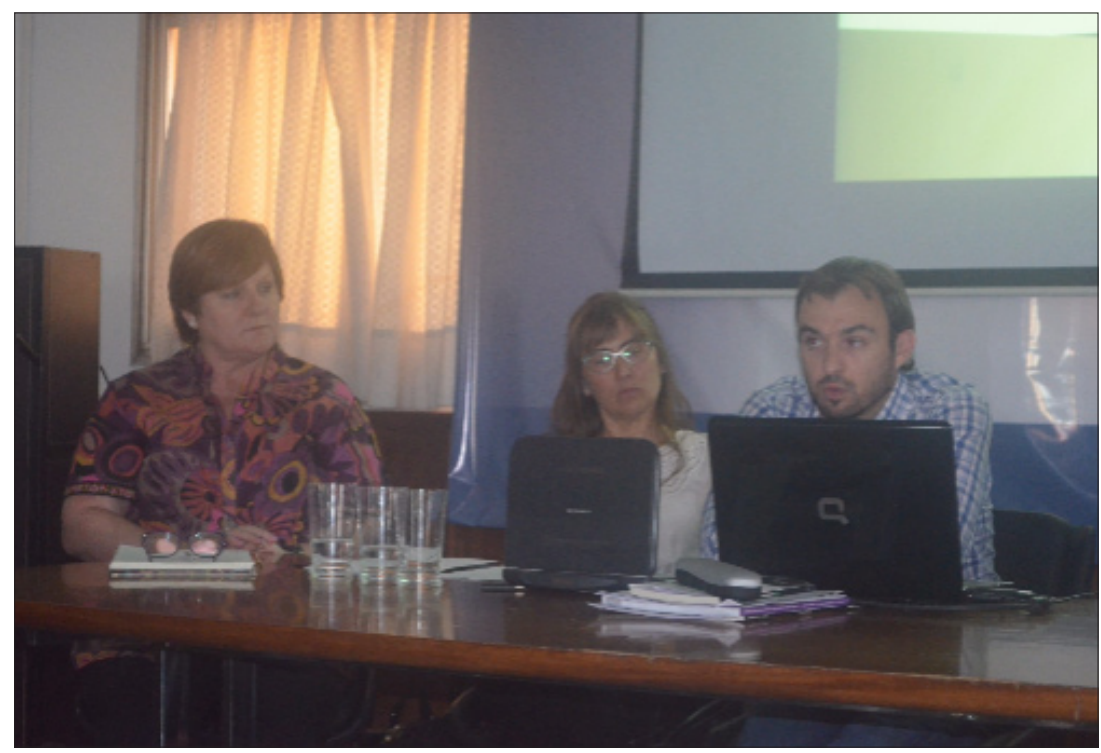

Panel Guerra en Siria. La trama geopolitica regional y sus consecuencias en la población civil. Foto: gentileza de Melina Acosta (2015)

A este escenario, se le suman las acciones de las diversas facciones armadas que complejizan aún más el entramado de las relaciones políticas, entre las que se destaca claramente el Estado Islámico (EI), también llamado Estado Islámico de Irak y el Levante (EIIL o ISIS según sus siglas en inglés) o DAIISH, según la transliteración del árabe. Sus intervenciones causaron terror, tanto en Siria e Irak como en el resto del mundo, por 
el extremismo de sus acciones. En la actualidad, los combates entre las diversas fuerzas, han mermado la capacidad territorial del ISIS que debió retirarse de vastos territorios conquistados en años anteriores. En cambio, sus actividades terroristas se dispersaron por el resto del mundo bajo la forma de atentados reivindicados por el mismo grupo o sectores adscriptos a su lucha aún sin pertenecer orgánicamente a su estructura constitutiva. Estados de cuatro continentes (Asia, África, Europa y América) han sido víctimas de sus agresiones, en un cambio de estrategia de alcance global, donde el ISIS intenta recobrar el protagonismo en la región.

En el contexto actual, los ciudadanos refugiados y desplazados de Siria se transforman en un nuevo tipo de ciudadanos excluidos de su territorio, sin una vida digna y dependientes de la ayuda internacional. De acuerdo a lo expresado por Méndez (2011), esta es una de las secuelas más graves provocadas por las contiendas bélicas en distintas regiones del mundo y ocasionan el aumento del número de personas desarraigadas. La Geografía como ciencia social no puede ni debe estar ajena al tratamiento de estas problemáticas contemporáneas.

Es posible acceder a una variada producción científica respecto a esta temática (Saborido y Borreli, 2016; Ghotme Ghotme et al., 2015; Alba Rico, 2015; Naïr 2013 y 2012; Álvarez Osorio y Ruiz De Elvira, 2011; entre otros), que proviene de diferentes campos del conocimiento. El propósito de este artículo es realizar un análisis e interpretación desde una mirada geográfica que contemple el proceso histórico de conformación del territorio sirio, las múltiples causas que desencadenaron el conflicto, así como los actores sociales que intervienen, los intereses geopolíticos que construyen la trama territorial contemporánea y las consecuencias humanitarias sobre la población.

El texto está estructurado en tres apartados que responden metodológicamente, en primer lugar se ponen en discusión las relaciones geopolíticas regionales y los actores globales que intervienen en el territorio sirio. Al respecto, en base a informes de la Organización de Naciones Unidas (ONU) y de Institutos de investigación se construye la trama de vínculos geopolíticos regionales y globales (Estados Unidos, Federación Rusa y Turquía), se aborda el rol de ONU y de la Organización del Tratado del Atlántico Norte (OTAN), así como la emergencia del Estado Islámico de Irak y el Levante (ISIS).

En segundo lugar, se realiza el abordaje de la guerra civil en el contexto de la "Primavera Árabe" a partir del análisis de las condiciones sociales y políticas internas que movilizaron a la población y provocaron el desenlace de la guerra. Este apartado se sustenta en el análisis de publicaciones 
referidas al mundo árabe y la realidad territorial local. Para visibilizar las consecuencias sociales y económicas se comparó el Índice de Desarrollo Humano a lo largo de los últimos años.

Para finalizar se plantean las consecuencias sobre la población expresadas en los desplazamientos internos y en la población refugiada. Al respecto se toman los datos estadísticos proporcionados por el Comité Regional de Naciones Unidas para los Refugiados (ACNUR) con el propósito de interpretar las migraciones forzadas a la luz de los conceptos geográficos como desterritorialización y reterritorialización.

\section{El contexto geopolítico regional y los actores globales}

El abordaje del conflicto sirio en clave geopolítica posibilita el análisis de las diversas variables que entran en juego en el desarrollo de la guerra civil, en el marco de la dinámica de la región del Oriente Medio. Desde esta perspectiva, entonces, comprender a la Siria actual como un "estado fallido" puede otorgar una serie de herramientas conceptuales para interpretar la realidad. Los estados fallidos se caracterizan por las deficiencias en el cumplimiento de las funciones estatales básicas y en la provisión de servicio públicos esenciales, la pérdida del control territorial, el mayor riesgo de violencia directa sobre la población civil, la consiguiente violación a los derechos humanos, y la emergencia de zonas grises dentro de los límites del Estado, que escapan al ejercicio del poder estatal, entre otros aspectos (Méndez, 2011).

La interpretación de la dinámica del contexto regional es imprescindible para comprender la propagación conflictos recientes en Oriente Medio (Siria y Yemen) y la pervivencia de conflictos históricos, como el palestino-israelí (Cassen, 2012). Las revueltas árabes ${ }^{3}$ lograron en menos de un año el derrocamiento de tres autócratas árabes, Ben Ali en Túnez, Hosni Mubarak en Egipto y Muamar Gadafi en Libia.

La familia al-Assad gobierna desde hace más de cuarenta y cinco años en Siria. Tras la muerte de Hafezal-Assad, su hijo y actual presidente Basharal-Assad, toma el poder con perspectivas de reformas y cambios. Lo cierto es que la resistencia al régimen continúa y se mantienen rasgos de

3 Los golpes de Estado populares del mundo árabe no son revoluciones político-ideológicas sino revoluciones ciudadanas son perspectivas políticas claras. Barrieron con los poderes arraigados desde hace varias décadas, pero también con la organización política tradicional y sus partidos, sindicatos y jefes. No podemos citar un solo nombre de un líder legítimo y carismático que pretenda tomar el liderazgo de la revuelta (Conesa, 2012,33). 
permanencia vinculados con la limitación a la conformación de partidos políticos, la carencia de libertad de expresión y de prensa, represión y persecuciones internas (Khatib,2012).

La grave situación actual indica que lo que se inició como una demanda de mayores derechos por parte de la población, una participación política más amplia y libertad de expresión, se transformó en una guerra civil, reconocida como tal por la Organización de Naciones Unidas (ONU), entre las fuerzas del régimen y una diversidad de facciones opositoras, varias de ellas nucleadas en el Ejército Sirio Libre, que recibió el apoyo logístico y armamentístico de potencias extranjeras. La escalada llevó a que el conflicto fuera el centro de las discusiones en la reunión del G-20 desarrollada en San Petersburgo, Rusia, en septiembre de 2013. En ese momento, Estados Unidos, Francia y Reino Unido como coalición internacional, plantearon un ataque a Siria como el llevado a cabo contra Libia, gobernada por Gadafi, debido a las acusaciones contra el régimen de Al-Assad de haber utilizado armas químicas durante los enfrentamientos. Pero la oposición de Rusia y Chinafrenó la intervención inmediata. Rusia apostó a la propuesta de un "desarme químico" del régimen, y un apoyo al gobierno sirio. Apoyo que tiene diversas explicaciones, pero el anclaje de Rusia en la base naval geoestratégica de Tartús, en la costa mediterránea siria es un elemento clave. China se alió a Rusia y de este modo, postergaron la intervención directa que, en la actualidad, se consolida a partir del aprovisionamiento y sostenimiento de las potencias a cada sector de acuerdo a sus intereses estratégicos.

Un conflicto regional incontrolable, en el que la ONU se hunde como en un pantano. Era y siempre ha sido el cálculo de Asad. Su estrategia, además de la represión militar desconocida en la historia regional árabe, basada en el bombardeo de su propia población civil, actúa incentivando desde el primer día el odio interconfesional ya subyacente a la dominación del clan alauita-chiita del que era el representante, minoritario, pero que gobierna de manera despótica en Siria desde el golpe de estado perpetrado por su padre, Hafez el Asad, en 1970 (Naïr, 2013, p. 129).

La situación actual da cuenta de un entorno regional complejo con aliados y enemigos, la nación kurda que impulsa la creación de un Estado, los grupos terroristas, las alianzas militares y económicas, la tensión que genera la pertenencia a grupos religiosos como cristianos, drusos o musulmanes (chííes y dentro de éstos los alauitas, grupo minoritario en Siria frente a la mayorías unníes), entre otros aspectos, que se expresan en la cartografía regional.

A la complejidad de la guerra civil, un nuevo actor conflictivo desarrolla acciones y se instaló con consecuencias impredecibles en este escena- 
rio: la proclamación de un califato ${ }^{4}$ en los territorios del norte de Siria e Irak. El Estado Islámico (EI) o Estado Islámico de Irak y el Levante (ISIS según sus siglas en inglés), grupo yihadista, con su vertiginoso ascenso desde 2014 activa un alto riesgo para las soberanías e integridad territorial de Siria e Irak. Tanto las potencias regionales como mundiales deben diseñar ahora “(...) nuevos cálculos estratégicos, en medio de dilemas sobre cómo abordar un fenómeno complejo que trasciende los retos en el ámbito militar" (Fisas Armengol et al., 2015, p. 26).

En la emergencia del ISIS se observan tres rasgos básicos. En primer lugar, tiene un anclaje territorial (norte de Siria y de Irak) que desdibujó las fronteras políticas preexistentes en esta región del mundo árabe, fronteras heredadas del colonialismo europeo. El segundo, es su carácter "estatal" que se expresa en su posicionamiento territorial en un contexto de colapso de los "estados fallidos" de la región. Demostró que es más que un grupo terrorista, es autárquico, organiza el territorio militarmente, desarrolla actividades comerciales, destruye y, a su vez, construye infraestructuras de acuerdo a sus intereses. Por último, su expresión de poder a escala local, regional y global, está apoyada por modernas tecnologías de comunicación. Constituye una expresión de la radicalidad extrema, radicalidad que paradójicamente, atrae a jóvenes musulmanes y conversos de todo el mundo (Alba Rico, 2015).

La gran incertidumbre en torno al futuro de los conflictos de la región radica en la persistencia de muchos de ellos y la no visualización de su desenlace favorable. A los combates actuales en Siria e Irak, persiste de manera perpetua el enfrentamiento entre Israel y Palestina, se acentúa el caos y fragmentación territorial en Libia en el norte africano, desmejoran las perspectivas en Afganistán, continúan las luchas en Yemen y comienza a percibirse un desgaste progresivo de la situación en Líbano, sumado al intento de golpe de Estado en Turquía.

Las intervenciones, tanto diplomáticas vía la Organización de las Naciones Unidas (ONU), así como las armadas por intermedio de las potencias mundiales y regionales, no han logrado detener la violencia y el deterioro de la situación general de los países de Oriente Medio.

En torno a la dinámica del ISIS en Siria e Irak, los hechos dan cuenta de la capacidad organizativa del grupo terrorista, su autonomía financiera, el control de recursos naturales y la competencia paramilitar y mediática. Asimismo, su extremismo, el proyecto ideológico excluyente y el costo de un estado de guerra permanente constituyen sus flancos más debilitados

4 El "califato" es un tipo de gobierno islámico liderado por un califa, individuo que es considerado sucesor político y religioso del profeta Mahoma y líder de la comunidad de creyentes musulmanes (Fisas Armengol et al., 2015, p.34). 
(Jordán, 2016). Ambos países deberán bregar por la construcción de autoridades legítimas que posibiliten una representación efectiva de las diversas y heterogéneas comunidades que se hallan en su interior, como los sunnitas, los chiitas, los kurdos, quienes a su vez, presentan diferencias internas significativas que exponen al área a la posibilidad cierta de una verdadera fragmentación territorial.

De esta manera, el teatro de operaciones del Oriente Medio visibiliza también las rivalidades y antagonismos entre las potencias regionales. Arabia Saudita e Irán, líder sunnita de la península y exponente del mundo chiíta, respectivamente, intentan mutuamente influir decisivamente en las contiendas y contrarrestar el poder del rival. Claramente, sus intervenciones se manifiestan en las hostilidades que se llevan a cabo actualmente tanto en Siria como Yemen.

Por su parte, Turquía, el tercer actor geopolítico regional con aspiraciones hegemónicas, además de lidiar con múltiples frentes de conflicto al exterior de sus fronteras, debe añadir ahora la inestabilidad interna que reflejó el intento de golpe militar contra el gobierno en el mes de julio de 2016, luego de casi 20 años desde el último golpe de Estado. En el plano exterior, las enemistades manifiestas con los kurdos dejaron de ser la exclusiva preocupación del gobierno de Turquía. Los desequilibrios en Siria e Irak, antiguas posesiones otomanas, convierten a este país en un actor clave en la posible resolución de las confrontaciones. Su pertenencia desde hace décadas a la OTAN, le otorga una importancia particular entre las naciones de la encrucijada mediterránea entre Europa y Asia. En este contexto, un avance de las posiciones kurdas comprendería un acercamiento en su anhelo de búsqueda de mayor autonomía.

Mientras tanto, las potencias como la Federación Rusa, Estados Unidos y sus aliados europeos, asisten a la prolongación incesante de varios conflictos en la región con el agravante de los atentados terroristas en sus propios territorios. En este escenario con múltiples actores, donde despliega sus estrategias el ISIS, las intervenciones militares de EE.UU. y la OTAN, por un lado, más los ataques de Turquía y Rusia sobre territorio sirio, en donde también se localizan grupos kurdos, incrementaron la violencia con graves consecuencias para la población.

\section{De la "primavera árabe" a la guerra civil}

Al contrario de lo que sucedió en Túnez, Libia o Egipto, en Siria la revuelta social iniciada en 2011, con el propósito de derrocar el 
gobierno y reclamar reformas democráticas, no provocó hasta el momento la destitución del presidente Basharal-Assad. Lo que comenzó con una revuelta pacífica, lleva más de cuatro años de una guerra civil que enfrenta al régimen sirio con los rebeldes, el territorio está fragmentado entre áreas controladas por las fuerzas leales a al-Assad y fuerzas opositoras muy diversas y complejas. La denominada "primavera árabe" en Siria no condujo a un cambio político ni a una apertura democrática.

Son múltiples y al mismo tiempo complejas, las variables que impulsaron las revoluciones en los países árabes. Crisis económicas prolongadas, incremento del precio de los alimentos básicos, alta tasa de desempleo, especialmente de jóvenes que ven frustradas sus oportunidades de empleo y acceso a una vivienda. A esto se suman los regímenes gobernantes que suspenden o manipulan las garantías constitucionales de libertad y dignidad de los ciudadanos. Este movimiento expresa territorialmente la emergencia de una reconfiguración del espacio político: no se trata de un golpe de Estado típico, es mucho más que eso. El derrocamiento de las dictaduras en el mundo árabe no ha tenido nada que ver con el Islam. Tal como escribió Roy (2011), la generación de jóvenes árabes no está motivada por la religión, sino por conseguir democracia. Los manifestantes en las distintas plazas y ciudades reclamaban libertad, justicia, democracia y elecciones multipartidarias.

Las demandas de los ciudadanos expresadas territorialmente a través de las masivas rebeliones populares pusieron en cuestión la configuración del modelo de Estado vigente desde hacía décadas en el norte de África y en Oriente Medio.

Las dictaduras personalistas (militares o civiles), el parlamentarismo de partido hegemónico, las monarquías absolutas y las plutocracias hereditarias son los sistemas de gobierno predominantes en los países del arco que va del Atlántico al golfo Pérsico. El complemento de esta media luna islámica (Turquía, Líbano, Irán, Afganistán y Pakistán) son estados donde el autoritarismo (político y policial) y los poderes confesionales determinan la gobernanza (Ramonet, 2012, p. 188).

En las últimas décadas del siglo XX e inicios del siglo XXI, los estallidos sociales "democratizadores" se desarrollaron en casi todos los países de la región. En el mundo occidental tal vez no fueron suficientemente visibilizados osólo fueron interpretados como fundamentalismos religiosos. Sin embargo, y tal como sostiene Brieger, “(...) esta revuelta es profundamente democrática, aunque la mayoría de los gobiernos au- 
toritarios se sostengan gracias al respaldo de quienes dicen ser los portadores del mensaje universal de la democracia" (Brieger, 2011, p. 21). La permanencia de este tipo de gobiernos en la región es un rasgo común. Desde Marruecos a Egipto, hasta Siria, Qatar, Libia y Arabia Saudita, la variable que sufrió menos inflexiones en el mundo árabe, desde la independencia hasta hoy, es el carácter autocrático de los Estados. Tanto las monarquías como las repúblicas comparten esa característica y, a pesar de las crisis de legitimidad, lograron estabilizar, mantener y consolidar su poder durante varias décadas.

La "primavera árabe" en Siria se retrasó respecto a las movilizaciones ocurridas en Túnez, Egipto, Yemen, Libia o Bahréin. Fue a mediados del mes de marzo del año 2011 cuando la población civil se moviliza en las calles. "Esta ausencia inicial de movilización popular se explica por una serie de factores que han dificultado, desde el asalto al poder del partido Baas en 1963, la emergencia de una acción colectiva contestataria" (ÁlvarezOssorio, y Ruiz de Elvira, 2011, p.183). Estos autores sostienen que los factores que llevaron a la movilización popular tardía en Siria se pueden sintetizar en:

- factores de tipo étnico-confesional relacionados con la existencia de numeras minorías étnicas y religiosas que conformaban una sociedad fragmentada con intereses y posiciones contrapuestas frente al poder central.

- factores socioeconómicos que se caracterizaban por un discurso populista y social que coexistía con la liberalización económica que le aseguraba al régimen la credibilidad civil.

- factores de orden político. La popularidad de al-Assad se mantuvo desde se asunción en el año 2000 dado que representaba una propuesta de modernidad y cambio.

- Despolitización de la población. Durante las cinco décadas que gobernó el partido Baas no organizaron otros partidos políticos.

Este conjunto de factores no tenían suficiente peso como para generar movimientos sociales masivos. La popularidad del régimen parecía asegurar su continuidad. La situación de Siria en cuanto al Índice de Desarrollo Humano (Cuadro $\mathrm{N}^{\circ} 1$ ) muestra que durante las décadas de gobierno del partido Baas, dicho índice creció progresivamente hasta 2011, año en que comienza la guerra civil, y a partir del cual se deteriora. El país se posiciona en el puesto número 119 en 2011 y pasa al puesto 134 en 2015. 
Cuadro $\mathbf{N}^{\circ}$ 1: Evolución del Índice de Desarrollo Humano (IDH) -Siria

\begin{tabular}{|l|l|l|l|l|l|l|l|l|l|}
\hline 1980 & 1990 & $\mathbf{2 0 0 0}$ & $\mathbf{2 0 0 5}$ & $\mathbf{2 0 0 9}$ & $\mathbf{2 0 1 0}$ & $\mathbf{2 0 1 1}$ & $\mathbf{2 0 1 2}$ & $\mathbf{2 0 1 3}$ & $\mathbf{2 0 1 4}$ \\
\hline 0.497 & 0.553 & 0.586 & 0.621 & 0.630 & 0.639 & 0.632 & 0.623 & 0.608 & 0.594 \\
\hline
\end{tabular}

Fuente: Informe sobre Desarrollo Humano 2011 y 2015 -ONU.

Sin embargo, la conjunción de factores internos y externos desencadenó la guerra en todo el territorio. Las primeras movilizaciones convocadas en febrero de 2011 no tuvieron éxito, sin embargo, el 15 de marzo de ese mismo año, miles de personas se movilizaron en diferentes ciudades del país, en lo que se denominó "Día de la Ira". A partir de este momento se suceden reiteradas manifestaciones y comienza la represión por parte del gobierno, con los que se desencadena una escalada de violencia con la intervención de diversos actores.

Los conflictos armados en Siria continúan en 2016 con una intensificación de la tensión entre las diversas facciones enfrentadas. A la guerra civil se agregaron las intervenciones del ISIS desde Irak a través de apropiación territorial, ocupación de bases militares y el control de recursos naturales como yacimientos de petróleo y gas. En los combates también se encuentran involucrados no solo los grupos vinculados al Frente Islámico, la mayor coalición de fuerzas rebeldes en Siria, sino también el Frente al-Nusra (considerado como la filial siria de al-Qaeda) enfrentado a ISIS y otras fuerzas de la oposición siria. Hacia finales del año 2014 EE.UU., a la cabeza de la coalición liderada por la OTAN y con la anuencia de un grupo de países de la Liga Árabe (Bahrein, Jordania, Arabia Saudita, Qatar y Emiratos Árabes Unidos) comenzó los bombardeos contra posiciones de ISIS en territorio sirio, otorgando al conflicto una gran complejidad en el que se entrecruzan los diversos sistemas de alianzas (Fisas Armengol, V. et al, 2015).

Por lo expuesto en el párrafo anterior, la guerra civil que se está desarrollando en Siria puede ser definida como un conflicto asimétrico. De acuerdo a lo expresado por Méndez, se definen como conflictos asimétricos

\footnotetext{
(...) aquellos que se producen entre ejércitos regulares, a veces dotados de armamento sofisticado, y grupos armados irregulares, con armamento convencional, que en el pasado tuvieron a la guerrilla como su mejor exponente, a la que hoy se suman diversos tipos de fuerzas reclutadas y pagadas por diferentes señores de la guerra y los grupos terroristas (Méndez, 2011, p. 258-259).
}

En el caso de Siria, el gobierno está representado por los grupos leales a las fuerzas militares del régimen y del partido Baas. Además, se encuen- 
tran como aliados al gobierno, Shabiha, un grupo paramilitar leal al presidente y financiado por la familia al-Assad; el Frente Nacional Progresista, constituido por diversos partidos políticos, minorías drusa y cristina; y por último, el apoyo externo del Hezbollah libanés, y los gobiernos de Irán y Rusia (Ghotme Ghotme et al., 2015).

Figura $\mathbf{N}^{\circ}$ 1. Los frentes de la guerra y la fragmentación territorial

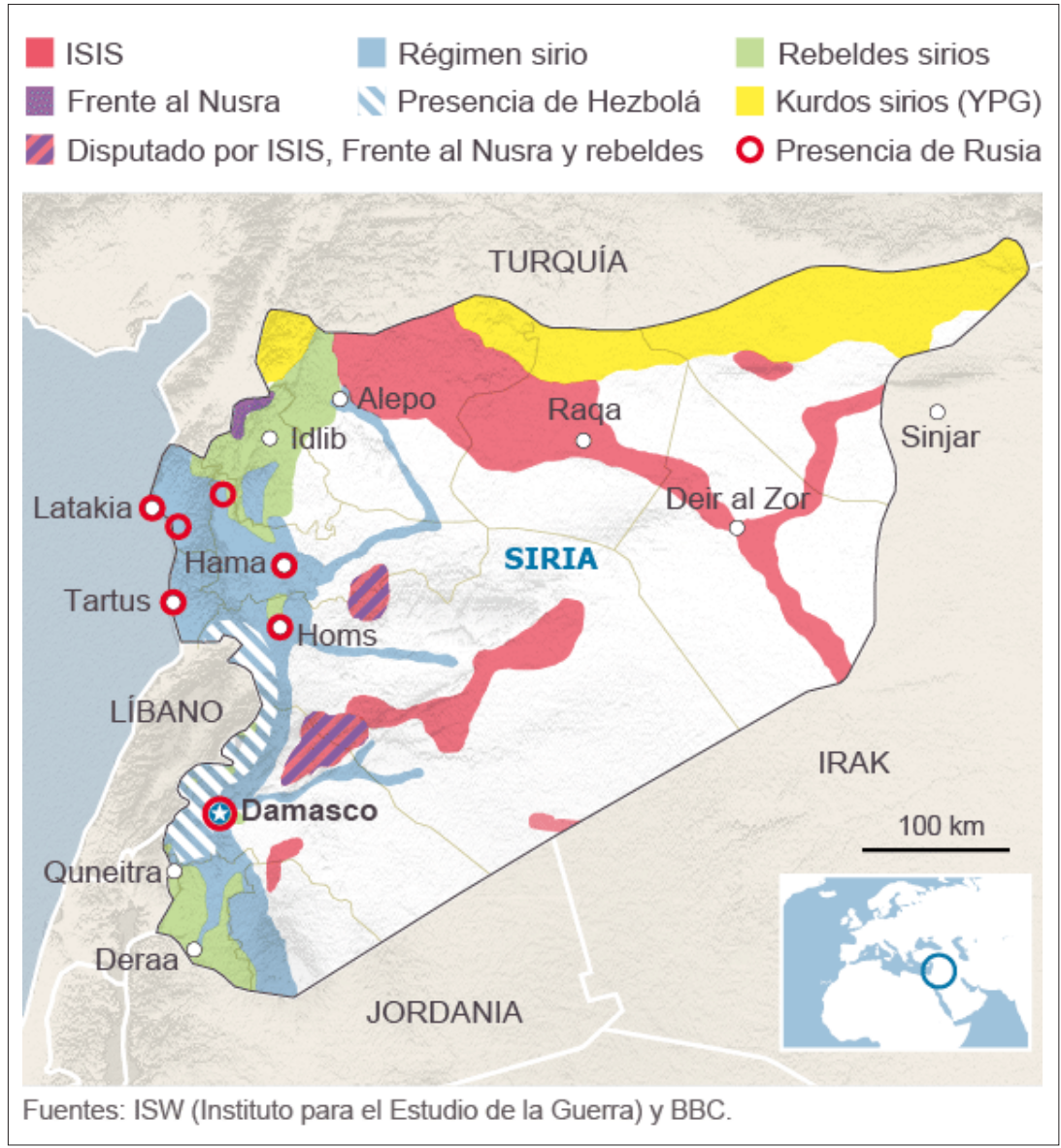

Fuente: Sancha, N., 2015.

La oposición al régimen de al-Assad está constituida por la Coalición Nacional Siria, un conjunto heterogéneo de opositores sunitas, partidarios de instaurar una democracia pluralista. Esta Coalición está formada por intelectuales disidentes, agrupaciones juveniles, los Hermanos Musulmanes de 
Siria, el Consejo Nacional Sirio y los Comités de Coordinación Local, constituyéndose en el brazo político de la oposición que opera desde el exilio, desde Qatar, y reconocida como el representante legítimo del pueblo sirio por parte de Estados Unidos y sus aliados. El grupo armado está constituido por el Ejército Libre de Siria, que a lo largo del conflicto sufrió cambios importantes en su estructura (muchos militantes están refugiados en Turquía y se sumaron a la milicia sirio-kurda y lucha contra el EI, y otros se desmovilizaron). El Ejército Libre de Siria es liderado por el Consejo Supremo Militar que agrupa rebeldes armados y desertores del ejército, grupos islamistas, apoyados por Arabia Saudita, Emiratos Árabes y Kuwait, y por el Consejo Nacional Kurdo (Ghotme Ghotme, et al., 2015). Por su parte, los grupos yihadistas más importantes que operan en Siria son: el Frente al-Nusra, grupo afiliado a al-Qaeda que se creó en enero de 2012 para derrocar el régimen de al-Assad, y está disperso en casi todo el territorio; el Estado Islámico (EI) o Estado Islámico de Irak y el Levante (ISIS) que comienza a actuar en 2013; y el Frente Islámico que surge también en 2013 por la fusión de siete grupos rebeldes (Ghotme Ghotmeet al., 2015).

El complejo mosaico de poder expresado sobre el territorio (Figura $\mathrm{N}^{\circ}$ 1) da cuenta de la existencia de regiones en Siria controladas por distintas fuerzas militares, y demuestra la incapacidad del Estado para ejercer la soberanía. El resultado es la configuración de un país fragmentado, donde la población está expuesta a un alto grado de vulnerabilidad.

\section{Dispersión territorial de la población y refugiados}

Tal como se puede observar en la Cuadro $\mathrm{N}^{\circ} 2$, donde se representan los países con mayor número de desplazados internos en el año 2011, Siria no registraba desplazamientos de población. Los datos indican que los países que se destacaban por el número de desplazados eran Colombia, Sudán, República Democrática del Congo, Somalia e Irak, entre otros. La suma total de desplazados en el año 2011 es significativamente menor a la cantidad de sirios que a la fecha (noviembre 2012) viven fuera de su lugar de residencia ${ }^{5}$. Esto da cuenta de la gravedad de la guerra. La mitad de

5 "No hay un lugar en todo el territorio sirio que no viva cotidianamente bombardeos atroces, escaramuzas despiadadas o asesinatos religiosos o políticos. Los tanques arrasan barrios enteros, los misiles caen sin control, los morteros estallan en medio de la noche y las balas de los francotiradores se cobran vidas, sin edades. Su población está exhausta. Casi no hay comida, ni agua potable, ni electricidad. La economía, que en su momento era próspera, se deshizo en pedazos" (Vittar, 2015). 
la población del país se desplazó de su hogar, lo que demuestra un fuerte impacto en la vida cotidiana de los habitantes y en la organización social, económica y política del país.

Cuadro $\mathrm{N}^{\circ}$ 2: Desplazamientos internos en distintos países del mundo

\begin{tabular}{|l|c|c|c|}
\hline \multicolumn{1}{|c|}{ País } & Comienzos de 2011 & Finales de 2011 & \% de cambio \\
\hline Afganistán & 351.000 & 448.000 & 27 \\
\hline Azerbaiyán & 592.000 & 599.000 & 1 \\
\hline Colombia & 3.672 .000 & 3.888 .000 & 6 \\
\hline Costa de Marfil & 517.000 & 127.000 & -75 \\
\hline Irak & 1.343 .000 & 1.332 .000 & -1 \\
\hline Kenia & 300.000 & 300.000 & 0 \\
\hline Paquistán & 952.000 & 452.000 & -52 \\
\hline $\begin{array}{l}\text { Rep. Democrática } \\
\text { del Congo }\end{array}$ & 1.721 .000 & 1.709 .000 & -1 \\
\hline Somalia & 1.463 .000 & 1.356 .000 & -7 \\
\hline Sudán & 1.526 .000 & 2.340 .000 & 53 \\
\hline
\end{tabular}

Fuente: Sassen, S. 2015, p. 72.

Desde que comenzó el conflicto bélico en Siria, el número de personas que abandonó sus hogares creció vertiginosamente. De acuerdo a los datos publicados por el Alto Comisionado de Naciones Unidas para los Refugiados (ACNUR), al mes de octubre de 2015 el conflicto desplazó de sus hogares a 4.180.631 personas que están localizadas en campos de refugiados en los países vecinos. Son millones de sirios registrados por el ACNUR en Egipto, Irak, Jordania, Líbano y Turquía (Cuadro $\mathrm{N}^{\circ} 2$ ). Por otra parte, hay 6,6 millones de desplazados internos en Siria (ACNUR, 2016) ${ }^{6}$. Estas cifras podrían ser aún más elevadas, ya que no todos los sirios que han huido de su país están registrados por ACNUR y respecto a los desplazamientos internos, se trata de cifras estimativas porque el relevamiento de datos es muy difícil dadas condiciones de guerra que prevalecen en el territorio. Siria, con 21.987.000 habitantes (World Statistics Pocketbook

6 Según el Informe sobre Desarrollo Humano 2015, en Siria existen 7.600.000 desplazados internos. La diferencia en los datos publicados da cuenta de las dificultades en el relevamiento de la información. 
2015), es el país que más población expulsó entre 2014 y 2015. Familias enteras se transformaron en migrantes forzados, desplazados, refugiados, inmigrantes legales e ilegales en Europa, solicitantes de asilo, todas estas categorías se aplican según corresponda, para definen la situación actual de la mitad de la población del país.

Según datos recientes de Syria Regional Refugee Response el número de refugiados ha crecido desde el año 2012. Se registran 2.733.044 refugiados en Turquía, 1.033.513 en Líbano, 117.168 en Egipto al 30 de junio de 2016; 657.433 en Jordania al 4 de julio de 2016 y 29.275 en otros países de Norte de África al 18 de mayo del mismo año. Cifras que suman un total de 4.819.828 personas (http://data.unhcr.org/syrianrefugees/regional.php\#).

Tal como se puede apreciar en el Mapa $\mathrm{N}^{\circ}$ 2, Turquía, Líbano, Jordania, Irak y Egipto son los países que organizaron campos de refugiados para acoger a los desplazados por la guerra, y además existen desplazados internos en el territorio sirio.

Figura $\mathbf{N}^{\circ}$ 2. Cartografía de los desplazados

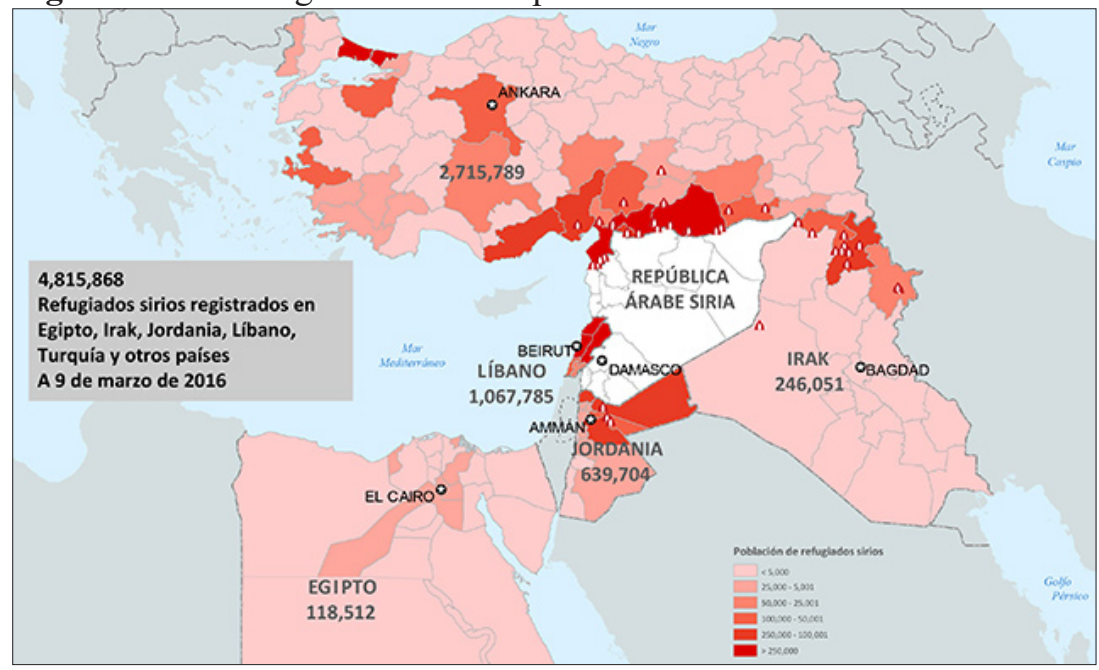

Fuente:http://www.acnur.org/que-hace/respuesta-a-emergencias/emergencia-en-siria/

Las solicitudes de asilo en países europeos registradas desde abril de 2011 hasta mayo de 2016 ascienden a 1.066 .844 y solo en el año 2014 se registraron 137.798. Los países que más solicitudes han recibido son Alemania y Serbia con 63\%; Suecia, Hungría, Austria; Holanda y Dinamarca con el $26 \%$ y otros países el $12 \%$ de las solicitudes (http://data.unhcr.org/ syrianrefugees/regional.php\#). 
La crisis siria es la mayor emergencia humanitaria a la que se enfrenta ACNUR.Los más afectados por esta crisis humanitaria, considerada la mayor de este siglo, son los niños y los ancianos (ACNUR, 2015).Esta agencia de ONU ofrece refugio, ayuda y asistencia a los sirios que necesitan protección. Los refugiados según la categoría definida por ACNUR, son aquellas personas que huyen para salvar sus vidas o preservar su libertad. La diferencia con los migrantes por razones económicas radica en que los refugiados tienen derecho a pedir asilo cuando puedan demostrar que proviene de un país en guerra o sufren persecuciones por motivos políticos, religiosos, de nacionalidad, entre otros, según lo prevé el Estatuto del Refugiado de la ONU de 1951y sus modificaciones de 1967.Las personas desplazadas por la guerra se convierten en refugiados tras una serie de etapas, las cuales se pueden sintetizar del siguiente modo:

- Abandono del hogar: los combates y amenazas son los principales motivos por los que una familia siria decide dejar su casa. Cuando las familias tienen niños pequeños, ese abandono se puede producir antes de que lleguen los combates, para proteger a los menores de los bombardeos y evitar que pasen miedo.

- Desplazamiento interno: los sirios suelen desplazarse unas siete veces antes de decidirse a abandonar el país. En un principio, los movimientos se producen dentro de la propia ciudad, luego, hacia regiones seguras.

- Salida del país: los refugiados suelen desplazarse por carretera. Los países que más sirios acogen son los que comparten fronteras. En muchas ocasiones, los varones vuelven varias veces al país para comprobar el estado de sus propiedades o para luchar.

- Instalación en campos de refugiados: los sirios suelen instalarse en campamentos gestionados por las autoridades locales y las agencias humanitarias o bien se aglutinan en asentamientos informales, pero también alquilan casas en ciudades y pueblos. Suelen agruparse por afinidad de religión, filiación familiar o incluso por pertenencia a la misma ciudad de la que partieron a causa de la guerra.

- Registro en el ACNUR: este organismo se encarga de registrar a los refugiados. Los desplazados en calidad de refugiados deben presentarse personalmente ante los funcionarios de la ONU, quienes hacen una entrevista antes de tramitar los papeles que les acreditan como refugiado.

- Asistencia humanitaria: una vez se obtienen los papeles que acreditan su condición de refugiados, las personas son susceptibles de recibir ayuda tanto de la ONU como de las ONG asentadas en la zona. Refugio, comida y saneamiento son las necesidades que suelen cubrirse. 
- Integración: la integración con la población autóctona es uno de los retos a los que se enfrentan tanto las agencias de la ONU y las ONG, así como las autoridades locales.

La crisis humanitaria tuvo un momento traumático durante septiembre de 2015, debido al desplazamiento masivo hacia Europa. Es considerada una crisis de refugiados en la que se manifiesta la ausencia de la dignidad y el incumplimiento del respeto por los Derechos Humanos. El derecho internacional contempla responsabilidades de los Estados ante los refugiados, por ello la ONU a través de ACNUR insta a los países a responder a la presente crisis de manera integrada, especialmente a los miembros de la Unión Europea. "El único modo de solucionar este problema es que la Unión Europea y todos sus Estados miembros pongan en marcha una estrategia común, basada en la responsabilidad, la solidaridad y la confianza" (ACNUR, 2015, p. 1).

En palabras de Sassen, la Agencia ACNUR "define la situación de refugio prolongado como una en que 25.000 o más refugiados del mismo país han estado en exilio por cinco años o más. (...) Estos son los expulsados que probablemente nunca volverán a una vida normal" (Sassen, 2015, p. 71). La autora sostiene que el impacto económico que la población refugiada tiene sobre los países es mayor en el sur global que en el norte. Afirma que "el impacto de los refugiados en la economía de Alemania fue mínimo, con 15 refugiados por cada dólar de su PIB per cápita. Evidentemente es posible que el impacto económico sea mínimo al tiempo que el impacto social es alto" (Sassen, 2015, p.75).

En este sentido, Kenneth afirma que "la crisis de refugiados no es tal" si se tiene en cuenta la cantidad de refugiados y la economía de los países europeos...,

La población de la Unión Europea es de aproximadamente 500 millones. La última estimación de la cantidad de personas que utilizan medios irregulares para entrar en Europa este año a través del Mediterráneo o los Balcanes es de aproximadamente 340.000. En otras palabras, el flujo de este ańo sólo supone 0.068 por ciento de la población de la UE. Teniendo en cuenta la riqueza de la UE y su avanzada economía, es difícil argumentar que Europa carece de los medios para absorber estos recién llegados (Kenneth, 2015, p. 2).

Del análisis precedente se puede sostener que la crisis no es económica sino social. El impacto visual, psicológico, político que produce la llegada de tanta cantidad de personas desestabiliza la tranquilidad europea. Mien- 
tras los que huyen de la guerra permanecen en campamentos de refugiados de los países limítrofes a la zona de conflicto el problema de los refugiados esta territorializado. La crisis se produce cuando estas personas arriban al territorio europeo y es ahí cuando la problemática de los refugiados se desterritorializa y se reterritorializa. De este modo, "Los inmigrantes y los refugiados plantean la tensión entre la protección de los derechos humanos y la protección de la soberanía del estado. Esta tensión es particularmente aguda en el caso de inmigrantes indocumentados, porque su mera existencia significa una erosión de la soberanía” (Sassen, 2001, p. 73).

\section{Reflexiones finales}

Las revoluciones populares iniciadas en marzo de 2011 en Siria no provocaron la transformación esperada y tampoco consiguieron un cambio político. Por el contrario, se intensificó el autoritarismo ejercido por el régimen sirio, dado que desde un primer momento el presidente Basharal-Assad apostó a la acción militar para conservar el poder y mantener su posición en el gobierno. Si bien durante el año 2011 se aprobaron algunas medidas que mostraban un incipiente inicio de reformas democráticas, finalmente los acontecimientos demostraron que el régimen vigente es incapaz de reformarse a sí mismo, y no tiene el propósito de iniciar una transformación hacia la democracia.

Por otra parte, en los cuatro años de duración, la crisis siria modificó su carácter, dado que pasó de una revuelta ciudadana democratizadora a una guerra interna con una activa intervención de actores globales y regionales. Dado que el control estatal está en manos del grupo minoritario alauí, esta circunstancia es utilizada por los grupos salafistas y yihadistas para definir una guerra sectaria. El ISIS encontró la oportunidad para desplegar sus acciones terroristas en un Estado sirio "fallido", con amplias regiones que escapan al control del gobierno de Basharal-Assad. Irán y Arabia Saudita, dos potencias regionales, se involucraron activamente en la guerra y convirtieron a Siria en el tablero geoestratégico donde se desarrollan las tácticas por el control de Oriente Medio. Por su parte, la comunidad internacional y los organismos internacionales competentes, son también responsables de la envergadura que alcanzó la guerra en Siria, en tanto observan los acontecimientos desde la distancia.

En síntesis, cuatro son las razones que explican la crisis humanitaria en que derivó esta guerra civil y originan el desplazamiento forzado de la mitad de la población del Estado sirio. En primer lugar, la crisis política y los recla- 
mos de los ciudadanos a partir de los movimientos sociales gestados durante las Revoluciones Árabes. Segundo, la represión militar emprendida por el propio Estado contra la población civil y las respuestas que se generaron expresadas en organizaciones paramilitares que desafían el poder estatal. Tercero, las acciones del Estado Islámico que no da tregua y aumentó su poder de acción a expensas del caos y debilidad del Estado sirio. Estado Islámico que ejerce el terrorismo y obliga a los sirios a convertirse al islam sunita, de no aceptar, tienen como opciones pagar un alto costo económico (multas, expropiaciones), irse del territorio o morir asesinados. Por último, las acciones desiguales de los países de la región y la comunidad internacional que no generan respuestas oportunas ante la grave situación humanitaria.

La guerra en Siria derivó en una crisis humanitaria que se trasladó fuera de las fronteras del Estado, incluso excede la región de Oriente Medio. Con el desplazamiento de miles de refugiados hacia Europa, hoy la problemática territorial de Siria se instaló en el corazón de la Unión Europea. El impacto mediático que produjo la imagen del niño muerto en una playa de Turquía hizo despertar las conciencias de los ciudadanos del mundo y con esto surgió la presión sobre las políticas migratorias. Europa convertida en fortaleza infranqueable con la presencia de barreras visibles e invisibles requiere repensar sus políticas de gestión migratorias e incorporar la perspectiva de los derechos humanos en la cuestión inmigratoria. Según Sami Naïr, esto podría "(...) llegar a ser una fuente de relegitimación del proyecto europeo" (Naïr, 2015, p.1).

Esta problemática revelala existencia de un conflicto transversal que expone ante los ojos del mundo los intereses, las contradicciones, las racionalidades y las manifestaciones del poder sobre un territorio, en una geografía regional que se consolida cada vez con mayor fragmentación. En este conflicto se pueden apreciar las expresiones de poder locales, regionales y globales sobre el territorio de Siria, así como las identidades étnicas y religiosas en tensión, que conducen a la desterritorialización de la población local junto con sus redes de articulación social y productiva, y a una nueva territorialización en los países vecinos, expresada en los campos de refugiados, y en Europa con el aumento de los migrantes solicitantes de asilo.

Las acciones protagonizadas tanto por los europeos como por los sirios remiten a hechos ocurridos en el pasado reciente. La Primera Guerra Mundial, la Guerra Civil Española, la Segunda Guerra Mundial o la Guerra en Yugoslavia, provocaron desplazamientos de población y refugiados. Estos episodios traumáticos, portadores de un gran peso simbólico, no lograron construir una memoria social colectiva que reivindique el respeto por los derechos humanos. 


\section{Referencias bibliográficas}

ACNUR (2015). Emergencia en Siria. Enhttp:// www.acnur.org/t3/que-hace/respuesta-aemergencias/emergencia-en-siria/[Consulta: 28 de agosto de 2015].

ACNUR (2016). Emergencia en Siria. Enhttp:// www.acnur.org/que-hace/respuesta-a-emergencias/emergencia-en-siria/[Consulta: 19 de julio de 2016].

ALBA RICO, S. (2015). La explosión de Estado Islámico. En El Atlas de la globalización, todas las claves del proceso que está cambiando el mundo.Pp 148-151. Alfieri, C., editor. Buenos Aires: Capital Intelectual.

ÁlVAREZ -OSORIO, I. y RUIZ DE ELVIRA, L. (2011). La intifada Siria: el ocaso de los Assad. En Informe sobre las Revueltas Árabes. Túnez, Egipto, Yemen, Bahréin, Libia y Siria. Pp.181-222. Edición de Gutiérrez de Terán, I. y Álvarez -Ossorio, I. Madrid: ediciones del oriente y del mediterráneo.

BRIEGER, P. (2011). Diez claves para comprender las revueltas. En Le Monde diplomatique $N^{\circ} 143(20-21)$. Buenos Aires: Capital Intelectual.

CASSEN, B. (2012). Panorama geopolítico antes de las insurrecciones árabes. En Las revoluciones árabes. Causas, consecuencias e impacto en América Latina. Pp. 11-21.Naïr, Samiet al. Buenos Aires: Capital Intelectual.

CONDE ZAMBADA, G. (2013). Turquía, Siria e Iraq entre amistad y geopolitica. México: El Colegio de México.

CONESA, P. (2012). Un siglo de revueltas árabes.En Las revoluciones árabes. Causas, consecuencias e impacto en América Latina. Pp.22-34.Naï, Sami et al. Buenos Aires: Capital Intelectual.

FISAS ARMENGOL, V., ROYO ASPA, J., URGELL GARCÍA, J., URRUTIA ARESTIZÁBAL, P., VILLELLAS ARIÑO, A. y VILLELLAS ARIÑO, M. (2015). Alerta 2015! Informe sobre conflictos, derechos humanos y construcción de paz. Barcelona: Icaria.

Enhttp://escolapau.uab.es/img/programas/alerta/ alerta/15/alerta15e.pdf[Consulta: 15 de septiembre de 2015].

GHOTME GHOTME, R.A.; GARZÓN GARZÓN, I.V. y CIFUENTES ORTIZ, P.A. (2015). Las relaciones internacionales de la guerra civil siria a partir de un enfoque regional: hege- monía y equilibrio en Medio Oriente.Pp.1332. En Revista Estudios Políticos $N^{\circ} 46$.

Enhttps://aprendeenlinea.udea.edu.co/revistas/index.php/estudiospoliticos/article/ viewFile/18771/17923[Consulta: 10 de septiembre de2015].

INFORME DE DESARROLLO HUMANO 2015. Programa de Naciones Unidas para el Desarrollo. En http://hdr.undp.org/sites/default/ files/2015_human_development_report overview_-_es.pdf [Consulta: 28 de julio de $2016]$.

INFORME DE DESARROLLO HUMANO 2011. Programa de Naciones Unidas para el Desarrollo. En http://hdr.undp.org/sites/default/ files/hdr_2011_es_complete.pdf[Consulta 28 de julio de 2016].

JORDÁN, J. (2016).Panorama estratégico 2016. Madrid, Instituto de Estudios Estratégicos Español. En http://www.ieee.es/Galerias/fichero/panoramas/Panorama_Estrategico_2016. pdf[Consulta 28 de julio de 2016].

KENNNETH, R (2015). La crisis de los refugiados que no es tal. TheHuffington Post (4 de septiembre de 2015).Enhttp://www. huffingtonpost.es/kenneth-roth/la-crisis-derefugiados-q_b_8086350.html[Consulta 7 de septiembre de 2015].

KHATIB, D. (2012). El despertar de los árabes. EnLas revoluciones árabes. Causas, consecuencias e impacto en América Latina. Pp.64-79.Naïr, Sami et al. Buenos Aires: Capital Intelectual,

MÉNDEZ, R. (2011).El nuevo mapa geopolítico del mundo. Valencia: Tirant Lo Blanch.

NAÏR, S. (2013).¿Por qué se rebelan? Revoluciones y contrarrevoluciones en el mundo árabe. Madrid: Capital Intelectual.

NAÏR, S. (2015).“¿Guerra contra la inmigración?” Diario El País (3 de septiembre de 2015). Enhttp://elpais.com/elpais/2015/09/03/ opinion/1440591701_435098.html[Consulta: 9 de septiembre de 2015 ].

RAMONET, I. (2012).“¿Hacia qué nuevo “sistema mundo"?’EnLas revoluciones árabes. Causas, consecuencias e impacto en América Latina, Naïr, Sami et al. Buenos Aires: Capital Intelectual, 176-193.

ROY, O. (2015). “¿Dónde han ido a parar los islamistas?" Diario El País (5 de febrero de 
2011) Enhttp://elpais.com/diario/2011/02/05/ internacional/1296860407_850215. html[Consulta: 11 de septiembre de 2015].

SABORIDO, M. y BORRELI, M. (2016). Historia del fundamentalismo islámico: desde sus orígenes hasta el ISIS,Buenos Aires: Biblos.

SANCHA, N. (2015). El respaldo militar ruso a Siria da oxígeno a Bachar el Asad. Diario El País (28 de noviembre de 2015) En http://internacional.elpais.com/internacional/2015/11/28/ actualidad/1448741655_065928. html[Consulta 10 de septiembre de 2015].

SASSEN, S. (2001). ¿Perdiendo el control? La soberanía en la era de la globalización. Barcelona:Bellaterra.

SASSEN, S. (2015). Expulsiones. Brutalidad y complejidad en la economía global. Buenos Aires, Katz.
SYRIA REGIONAL REFUGEE RESPONSE (2016).En:http://data.unhcr.org/syrianrefugees/regional.php\#[Consulta: 19 de julio de 2016].

VITTAR, D. (2015).Siria, el país en guerra que más población expulsa. Diario Clarín (28 de agosto de 2015).En http:/www.clarin.com/ mundo/Refugiados-Inmigrantes-EuropaSiria-tragedia_humanitaria_0_1420658359. html[Consulta 19 de septiembre de 2015].

WORLD STATISTICS POCKETBOOK 2015. Nueva York, Naciones Unidas. Enhttp://unstats.un.org/unsd/pocketbook/World_Statistics_Pocketbook_2015_edition.pdf[Consulta 22 de julio de 2016]. 